\title{
LCM for Transport and Mobility
}

\author{
Stephan Krinke and Mara Neef
}

\begin{abstract}
LCM studies of industry and academia show the increasing importance of implementing life cycle thinking in the transport and mobility sector. Tools facilitating the use of LCA in product development processes increase the relevance of this topic in companies. OEMs use LCM as decision support for decarbonisation strategies and operationalization of greenhouse gas reduction targets. Next to environmental impacts, financial and social aspects are considered for a holistic assessment of vehicles. Regional impacts of alternative fuels and power trains need to be considered to support the development of sustainable mobility strategies in nation states. Regional specifics are also included in new data sets for modelling flat steel production along the value chain. Introducing voluntary credit transfer options in automotive legislation is proposed to incentivize low-carbon innovations throughout the whole life cycle of vehicles.
\end{abstract}

\section{Implementing Life Cycle Management in Transport and Mobility Industry}

In the Open Hybrid Lab Factory (OHLF) in Wolfsburg LCM is implemented throughout the design and manufacturing process of eco-efficient lightweight components. For this reason, an approach to interpret and apply LCA results in an effective way during different development and production steps is necessary. However, most of the involved design and production experts have no background in LCA. In order to facilitate the use Life Cycle Engineering (LCE) by non-LCE experts, a tool that allows for intuitive handling of inventory data and fast

\footnotetext{
S. Krinke $(\square)$

Volkswagen AG, Environmental Affairs, Letter Box 1896,

38436 Wolfsburg, Germany

e-mail: stephan.krinke@volkswagen.de

M. Neef

Volkswagen AG, Environmental Affairs Product, Letter Box 1774,

38436 Wolfsburg, Germany

(C) The Author(s) 2018

E. Benetto et al. (eds.), Designing Sustainable Technologies,

Products and Policies, https://doi.org/10.1007/978-3-319-66981-6_20
} 
interpretation of results was developed [1]. The integrated engineering process is visualized on a number of screens to show system interdependencies. Like this, material choices or manufacturing processes can be compared and evaluated fast and effectively from a life cycle point of view. In the future, environmental hotspots and trade-offs are visualized via spatial representation and cluster heat maps.

Likewise, Henkel set up an LCA tool (Henkel Easy LCA) to facilitate the use of LCA by non-LCA experts in the development process of new products [2]. The goal was to develop a streamline LCA tool with the highest level of detail necessary to make substantiated decisions in a first-tier assessment. For example, with the help of the tool, used raw materials can be assessed in less than two minutes. For higher-tier assessments, LCA specialists can be consulted for more detailed analyses. Until now, only greenhouse gas (GHG) emissions are considered in the raw materials assessment though water consumption will be included next. Henkel Easy LCA is also used to model and assess the logistics of products. It includes intermodal shifting, warehousing and capacity utilization.

At BMW, Life Cycle Sustainability Assessment (LCSA) on a component level was developed and adopted [3]. The three sustainability dimensions are assessed in an integrated way by combining Life Cycle Costing (LCC), Social-LCA (S-LCA) and LCA. Criticality points of up to 100 represent the respective impacts in each dimension caused by a specific component. The dimensions are equally weighted so that as a result, the average of criticality points of all dimensions show the relative performance of the assessed component in relation to all other components used. When applying LCSA it is possible to generate a higher environmental or financial impact by choosing a material that causes least negative social impacts. The goal, however, is to improve the vehicle's impacts in all of the sustainability dimensions.

At Volkswagen, different powertrains and fuels are assessed with LCA considering current circumstances and developments until 2030 to provide long-term support for the Group's decarbonisation strategy [4]. Different power trains are compared via the Performance Feel Index that assures a comparison of vehicles with similar user experiences in terms of overall driving dynamics. The whole life cycle is assessed to avoid burden shifting between life cycle phases when altering the fleet's power train and fuel composition. Like this, main drivers for efficiency improvements are analysed. The study showed that all power train systems still have significant improvement potentials. Special effort should be put into reducing the carbon dioxide burden of lithium-ion battery production, e.g. via energy efficiency, green energy supply and closed-loop recycling.

Similarly, at Toyota a life cycle approach is pursued to reach their 2050 target of reducing carbon emissions by $90 \%$ compared to 2010 [5]. Toyota will therefore focus on hybrid and fuel-cell vehicles powered with renewable energy and alternative fuels. Their LCAs further show that wrought alloy aluminium has a comparatively low environmental impact and should therefore be used for light-weight materials. The supply of needed quantities of wrought alloy aluminium is problematic though. Cooperation between academia, OEMs and other industries is proposed to solve the supply problem and develop more detailed data sets on the re-use of aluminium in the automotive industry. 
An LCA study by the Zurich University of Applied Sciences focused on synthetic power-to-gas as fuel for transportation with a Volkswagen Golf as reference car [6]. It showed that if synthetic power-to gas is produced with renewable energy, it emits less GHG per kilometre than fossil gas. Though at the moment, the Swiss grid mix includes a high share of nuclear power so that the electricity consumption of the electrolysis causes $51 \%$ of the overall impact. Additional recommendations are improving the electrolysis efficiency and using industrial waste gases as carbon dioxide source rather than atmospheric carbon dioxide to be competitive with conventional natural gas production.

The Japanese National Institute of Advanced Industrial Science and Technology assessed whether hydrogen is a suitable automotive energy carrier in Japan [7]. It was assumed that the hydrogen would be produced in Australia and subsequently transported to Japan. The LCA study showed that the hydrogen source, producer and transport need to be evaluated regionally in order to give meaningful results. Generally, liquid hydrogen should be produced with renewable energy to reduce its environmental impact. Within the assessed scenarios, hybrid vehicles cause the overall lowest environmental impact followed by hydrogen-powered and gasoline-powered vehicles.

The German Stahlinstitut VDEh developed regional specific datasets for flat steel products that facilitate a detailed analysis along the value chain [8]. The motivation for realizing the project was providing suitable data for customers and governments interested in modelling steel recycling. As steel producers either use iron ore or scrap to produce flat steel, both strategies are available in the datasets. In order to model steel recycling, the multiple recycling approach was applied. As a result, after including six recycling steps, the carbon dioxide burden of $1 \mathrm{~kg}$ of steel is reduced by $50 \%$.

\section{Policy Framework}

A study presented by the Technical University Berlin proposes an approach to foster sustainable mobility by integrating a life cycle perspective in automotive legislation [9]. Although policies concerning the automotive sector are becoming more relevant they do not include an LCA point of view yet but mainly focus on regulating tailpipe emissions. As the introduction of BEVs is shifting the environmental burden from the use to the production phase, a life-cycle approach in policies is needed to display this development. Instead of introducing a single life-cycle based policy tailored to vehicles, voluntary credit options should be operationalized within existing systems. Until now, automotive OEMs have no policy advantage if they save emissions in the production. Therefore, a credit transfer should be facilitated that values low-carbon innovations in the manufacturing phase. Hence, improving the environmental burden of vehicles throughout the whole life cycle becomes more attractive for OEMs. 


\section{Conclusions}

The session on LCM in transport and mobility underlined the necessity of including a life cycle perspective in the development of sustainable solutions in the sector. Companies and governments use a life cycle approach to develop decarbonisation strategies and operationalize targets. LCM is applied by industry to foster climate-friendly innovations from the design to end-of-life phase of materials, components and final products. Streamline LCA tools help disseminating life cycle thinking and effective implementation of LCA results by different occupational groups. By shifting the current focus on tailpipe emission regulations to a life cycle perspective in automotive legislation, the use of LCM by OEMs could further be consolidated.

\section{References}

1. Kaluza A, Kleemann S, Walk W, Vietor T, Herrmann C, Integrating life cycle engineering in the development of eco-efficient lightweight concepts.

2. Otte N, Singh R, Engelmann K, Tolls J, Nawaz M, Parametric LCA for a first tier assessment of products by the example of logistics.

3. Tarne P, Wagner V, Finkbeiner M, Adopting Life Cycle Sustainability Assessment in the Automotive Industry.

4. Plaga B, LCA comparison of power trains and fuels today and 2030 .

5. Denis R, The Toyota 2050 Environmental Challenges.

6. Wettstein S, Stucki M, Synthetic PtG as Fuel for Transportation.

7. Kudoh Y, Kitagawa N, Muramatsu R, Ozawa A, Genchi Y, Environmental Footprint Profiles of Hydrogen as Automotive Energy.

8. Hatscher N, Kroop S, Mayr R, Meincke A, Mohr L, Redenius A, Schuster S, Regional specific LCA data of flat steel products for detailed analysis along the value chain.

9. Lehmann A, Berger M, Finkbeiner M, Life cycle-based $\mathrm{CO}_{2}$ emission credits - an approach to foster sustainable mobility by integrating a life cycle perspective into automotive legislation.

Open Access This chapter is licensed under the terms of the Creative Commons Attribution 4.0 International License (http://creativecommons.org/licenses/by/4.0/), which permits use, sharing, adaptation, distribution and reproduction in any medium or format, as long as you give appropriate credit to the original author(s) and the source, provide a link to the Creative Commons license and indicate if changes were made.

The images or other third party material in this chapter are included in the chapter's Creative Commons license, unless indicated otherwise in a credit line to the material. If material is not included in the chapter's Creative Commons license and your intended use is not permitted by statutory regulation or exceeds the permitted use, you will need to obtain permission directly from the copyright holder. 